\title{
Qualidade de sementes de Hancornia speciosa Gomes em função do tempo de secagem
}

\section{Quality of Hancornia speciosa Gomes seeds in function of drying periods}

\author{
Paulo César Gomes dos Santos ${ }^{1}$; Edna Ursulino Alves ${ }^{2 *}$; Roberta Sales Guedes ${ }^{3}$; \\ Kelina Bernardo Silva ${ }^{3}$, Edson de Almeida Cardoso ${ }^{4}$; Cosmo Rufino de Lima $^{4}$
}

\section{Resumo}

\begin{abstract}
A mangabeira (Hancornia speciosa Gomes), da família Apocynaceae é originária do Brasil. Seus frutos são obtidos principalmente de forma extrativista e sua propagação é realizada por meio de sementes. $\mathrm{O}$ objetivo da pesquisa foi avaliar o efeito da secagem da semente na emergência e crescimento inicial de plântulas de $H$. speciosa. O trabalho foi conduzido no Laboratório de Análises de Sementes do Centro de Ciências Agrárias da Universidade Federal da Paraíba (CCA/UFPB), onde as sementes foram postas para secar sobre papel toalha em condições de laboratório pelos seguintes períodos: 0 (sem secagem), 24, 48, 72, 96, 120 e 144 horas. Determinou-se o teor de água, a porcentagem, primeira contagem e índice de velocidade de emergência, bem como o comprimento e a massa seca de plântulas. O delineamento experimental foi inteiramente ao acaso, com sete tratamentos em quatro repetições de 25 sementes. O teor de água das sementes foi reduzido de 56 para 12\% após 144 horas de secagem; a emergência máxima (73\%) ocorreu após 33 horas de secagem; na primeira contagem as maiores porcentagens de emergência (67\%) foram obtidas após 16 horas de secagem; os maiores índices de velocidade de emergência $(0,62)$ ocorreram após 21 horas de secagem; o comprimento da raiz reduziu linearmente ao longo da secagem, enquanto constatou-se maior comprimento da parte aérea $(4,96 \mathrm{~cm})$ quando as sementes foram submetidas à secagem por 57 horas. A secagem das sementes de $H$. speciosa é recomendada por até 48 horas.
\end{abstract}

Palavras-chave: Mangaba, sementes recalcitrantes, viabilidade, frutífera nativa

\begin{abstract}
Hancornia speciosa Gomes (Apocynaceae), a fruiting plant originated from Brazil, has fruits obtained mainly by extractivism and its main form of propagation is by seeds. The objective of this research work was to evaluate the effect of drying on emergency and initial growth of seedlings of $H$. speciosa. The work was developed in the Laboratory of Analyses of Seeds (CCA/UFPB), where the seeds were put to dry on towel paper in the laboratory environment conditions for the following periods: 0 (without drying), 24, 48, 72, 96, 120 and 144 hours. The evaluations were: water content, percentage of emergency, first count and index of emergency speed, as well as length and dry mass of seedlings. The experimental design
\end{abstract}

1 Aluno de graduação em Agronomia do Departamento de Fitotecnia, CCA-UFPB- Universidade Federal de Paraíba; Areia - PB. E-mail: paulo_cgs@hotmail.com

2 Prof ${ }^{a}$. Adjunta do Depto. de Fitotecnia, CCA/UFPB - Universidade Federal de Paraíba; Caixa Postal 02, CEP: 58.3987-000, Areia - PB. E-mail: ednaursulino@cca.ufpb.br

3 Doutorandas em Agronomia, Departamento. de Fitotecnia, CCA-UFPB - Universidade Federal de Paraíba. E-mail: roberta_ biologa09@yahoo.com.br; kelinabernardo@yahoo.com.br

4 Mestrandos em Agronomia, Departamento de Fitotecnia, CCA-UFPB- Universidade Federal de Paraíba. E-mail: edsonareia@ yahoo.com.br; cosmoagr@hotmail.com

* Autor para correspondência 
was entirely randomized, with seven treatments and four replications of 25 seeds. The water content of seeds decreased of 56 to $12 \%$ after 144 hours of drying, the maximum emergence (73\%) occurred after 33 hours of drying, in the first count the highest percentage of emergence $(67 \%)$ were obtained after 16 hours of drying, the highest index of emergence speed (0.62) occurred after 21 hours of drying, the root length decreased linearly along the drying process, while there was greater shoot length $(4.96 \mathrm{~cm})$ when the seeds were dried for 57 hours. The drying of $H$. speciosa seeds is recommended for 48 hours.

Key words: Mangaba, recalcitrant seeds, viability, native fruiting plant

\section{Introdução}

A mangabeira (Hancornia speciosa Gomes), da família Apocynaceae é uma planta encontrada naturalmente no Brasil, cuja distribuição ocorre nas regiões Centro-Oeste, Sudeste, Norte e Nordeste, com maior abundância nas áreas de tabuleiros e baixadas litorâneas do Nordeste, onde se encontra quase a totalidade da produção nacional (SOUZA et al., 2005). Os Estados da Paraíba, Bahia e Sergipe figuram entre os maiores produtores do país, onde os frutos são obtidos principalmente de forma extrativista (FONSECA; CONDÉ; SILVA, 1994). A planta, tipicamente tropical, possui grande potencial para exploração econômica, apesar dos poucos estudos sobre a cultura (FRANCO et al., 2008).

A árvore tem porte médio, podendo atingir entre 5 e $7 \mathrm{~m}$ de altura, possuindo frutos do tipo baga elipsóide ou esférica, de coloração esverdeada ou amarelada, com ou sem pigmentação vermelha, polpa branca, mole e fibrosa que recobre 2 a 15 sementes compridas e de forma discóide irregular, achatada, com hilo central, possui a testa de coloração marrom-amarelada, fina e o endosperma branco triangular (FAO, 1986; LORENZI, 2002). As sementes da mangabeira são consideradas recalcitrantes, isto é, não suportam dessecamento, perdendo rapidamente o poder germinativo assim que são retiradas do fruto (OLIVEIRA; VALIO, 1992; VIEIRA NETO, 2002).

De acordo com o nível de tolerância das sementes à dessecação, elas podem ser classificadas como ortodoxas, recalcitrantes e intermediárias (KRAAK, 1993). Durante a fase de maturação as sementes ortodoxas adquirem tolerância à dessecação, que é mantida após a dispersão. Todavia, nem todas as espécies têm sementes com comportamento ortodoxo e, nas sementes recalcitrantes não há a fase de secagem, sendo dispersas com alto conteúdo de água e são sensíveis à dessecação (BERJAK; PAMMENTER, 2000).

Nas sementes recalcitrantes, de forma geral, em nenhum momento do desenvolvimento se verifica tolerância à dessecação, motivo pelo qual há grande dificuldade em sua conservação (HARTMANN et al., 2001). Pammenter e Berjak (1999) mencionaram que a perda de água, durante o processo de secagem, em sementes recalcitrantes, causa várias alterações metabólicas, resultando na deterioração das mesmas. Essa diferença no comportamento das sementes pode ser considerada como resultado do processo de seleção natural, em concordância com as condições ambientais das regiões de origem da espécie (KERMODE, 1990; BARBEDO; MARCOS FILHO, 1998).

Nas sementes recalcitrantes há teores de água definidos como críticos, abaixo dos quais a viabilidade é reduzida, também há teores de água letais, relacionados à perda total da viabilidade (PRITCHARD, 1991; HONG; ELLIS, 1992; BILIA; MARCOS-FILHO; NOVEMBRE, 1999). Valores entre 27 a 38\% para o teor crítico (ANDRADE; PEREIRA, 1997; BILIA; MARCOS-FILHO; NOVEMBRE, 1999) e entre 12 a $22 \%$ para o teor letal têm sido reportados. O conhecimento dos teores de água crítico e letal para sementes de uma espécie é indispensável para o planejamento e a execução da secagem e do armazenamento das mesmas.

Apesar de haver grande diversidade de espécies nativas no Brasil que são de sementes recalcitrantes, são escassos os trabalhos com informações sobre a 
secagem das mesmas, tais como: Eugenia dysenterica DC. (ANDRADE et al., 2003), Archontophoenix alexandrae (Wendl. \& Drude) (MARTINS; BOVI; NAKAGAWA, 2003), Eugenia involucrata DC. (MALUF; BILIA; BARBEDO, 2003), Eugenia brasiliensis Lam. (KOHOMA; MALUF; BILIA, 2006) e Eugenia brasiliensis Lam., E. cerasiflora Miq., E. involucrata DC., E. pyriformis Camb., E. umbelliflora Berg. e E. uniflora L.) (DELGADO; BARBEDO, 2007).

Diante do exposto, o objetivo do trabalho foi avaliar o efeito de diferentes períodos de secagem da semente na emergência e crescimento inicial de plântulas de $H$. speciosa.

\section{Material e Métodos}

O experimento foi conduzido no Laboratório de Análise de Sementes (LAS), do Centro de Ciências Agrárias da Universidade Federal da Paraíba (CCA/ UFPB), Areia - PB. Os frutos de H. speciosa foram provenientes de um pomar pertencente à Empresa Estadual de Pesquisa Agropecuária da Paraíba S.A. - EMEPA, unidade de João Pessoa - PB, os quais foram coletados maduros, embaixo de diferentes plantas, acondicionados em sacos plásticos e conduzidos para o laboratório. O despolpamento foi realizado manualmente com auxílio de uma peneira e, em seguida as sementes foram lavadas em água corrente para retirada da mucilagem remanescente. Após o beneficiamento, as sementes foram postas sobre papel toalha para secar sob condições ambientais de laboratório (temperatura média de $24,5 \pm 0,5^{\circ} \mathrm{C}$ e umidade relativa média de $78 \pm 3 \%$ ) pelos seguintes períodos: 0 (sem secagem), 24, 48, 72, 96, 120 e 144 horas. Em seguida as sementes foram submetidas às seguintes determinações e testes:

Teor de água - $\mathrm{O}$ teor de água foi determinado em estufa regulada a $105 \pm 3^{\circ} \mathrm{C}$, durante 24 horas, conforme as Regras para Análise de Sementes (BRASIL, 1992), utilizando-se quatro repetições de 15 sementes para cada período de secagem.
Emergência - Após cada período de secagem quatro repetições com 25 sementes por tratamento foram semeadas em badejas plásticas com dimensões de $0,45 \times 0,30 \times 0,07 \mathrm{~m}$, contendo como substrato areia lavada e esterilizada em autoclave. A semeadura foi a uma profundidade de dois centímetros, cuja umidade do substrato foi mantida por meio de regas diárias. As contagens foram iniciadas aos 27 dias e continuaram até os 61 dias após a semeadura, onde se consideraram as plântulas com a parte aérea acima do substrato.

Primeira contagem de emergência - A primeira contagem foi conduzida juntamente com o teste de emergência, cuja avaliação foi realizada aos 35 dias após a semeadura.

Índice de velocidade de emergência (IVE) - Determinado também em conjunto com o teste de emergência, constando de contagens diárias do número de plântulas emersas, cujo índice foi calculado conforme a fórmula proposta por Maguire (1962).

Comprimento de plântulas - Após a contagem final do teste de emergência, as plântulas normais de cada repetição foram submetidas às medições da raiz primária e da parte aérea, com auxílio de uma régua graduada em centímetro. Os resultados foram expressos em cm/plântula.

Delineamento experimental e análise estatística - A análise estatística dos dados foi realizada utilizando o delineamento experimental inteiramente ao acaso, com sete tratamentos, em quatro repetições de 25 sementes cada. Os dados foram submetidos à análise de variância e de regressão polinomial.

\section{Resultados e Discussão}

O teor de água inicial das sementes de $H$. speciosa após a coleta e despolpamento foi de $56 \%$ (Figura 1), e, durante o processo de secagem foi diminuindo gradativamente, atingindo $31 \%$ após 72 horas e chegando a $12 \%$ após 144 horas de secagem. Observa- 
se, portanto, que houve redução no teor de água das sementes com o aumento do tempo de secagem.

A sensibilidade de sementes recalcitrantes ao dessecamento envolve uma complexidade de componentes relacionados às características bioquímicas e fisiológicas intrínsecas à espécie e a alguns fatores, tais como velocidade e temperatura de dessecação (KOVACH; BRADFORD, 1992; BERJAK; VERTUCCI; PAMMENTER, 1993).

Para a percentagem de emergência de plântulas (Figura 2), observou-se que houve, inicialmente, um aumento nesse parâmetro até as primeiras 33 horas, com $67 \%$ no período inicial (sem secagem) e emergência máxima de $73 \%$. Logo após ocorreu redução na porcentagem de emergência, chegando a $9 \%$ às 144 horas de secagem. Assim, nota-se que a emergência de plântulas oriundas de sementes com teor de água de até $43 \%$ não foi prejudicada pela desidratação, todavia, quando o teor de água foi reduzido para 38\% (após 48 horas de secagem), houve uma redução gradativa da porcentagem de emergência.

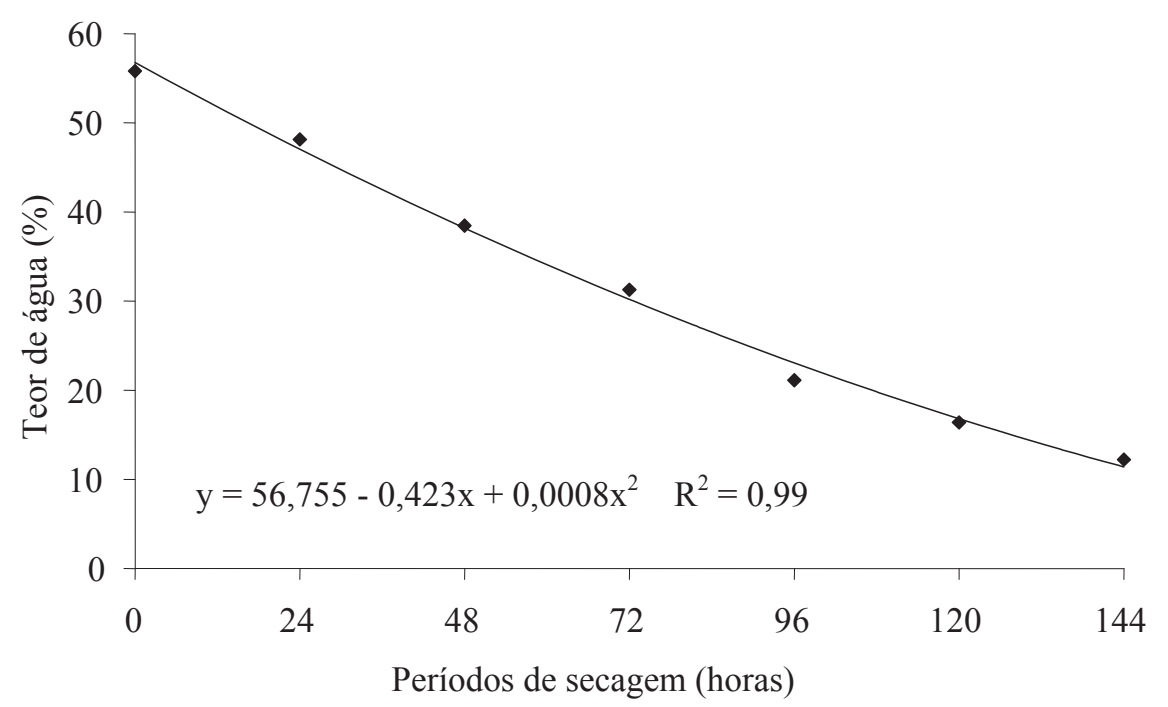

Figura 1. Teor de água de sementes de Hancornia speciosa em função de diferentes períodos de secagem.

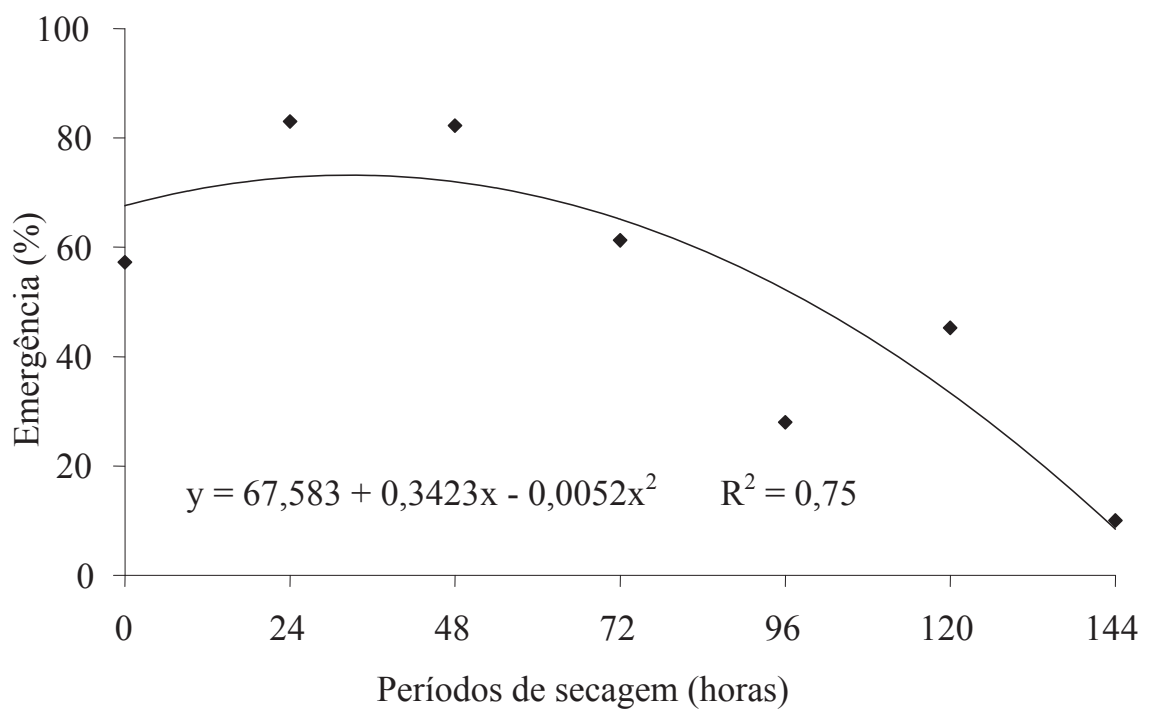

Figura 2. Emergência de plântulas de Hancornia speciosa submetidas a diferentes períodos de secagem. 
A secagem, provavelmente, provocou danos aos tecidos vitais das sementes, como o embrião, o que explicaria a redução drástica da emergência das plântulas após períodos prolongados de secagem. Em trabalhos conduzidos por Oliveira e Valio (1992), Salomão, Santos e Mundim. (2004) e Barros (2006) a redução na germinação de sementes de $H$. speciosa ocorreu com teor de água abaixo de $25 \%$.

Nas sementes recalcitrantes em nenhum momento do desenvolvimento se verifica tolerância à dessecação, motivo pelo qual há grande dificuldade em sua conservação (HARTMANN et al., 2001). A baixa porcentagem de germinação de sementes de H. speciosa pode está relacionada ao fato de suas sementes serem recalcitrantes (OLIVEIRA; VALIO, 1992; LORENZI, 2002).

$\mathrm{Na}$ presente pesquisa, teores de água inferiores a $23 \%$ proporcionaram redução do porcentual de emergência e do vigor das plântulas, sendo que à medida que ocorreu a desidratação com valores abaixo de $12 \%$ observou-se a mortalidade quase que total das sementes, evidenciando a faixa de teor de água letal. Essas observações confirmam as de Bewley e Black (1994), segundo as quais, as membranas se desorganizam quando as sementes atingem teores de água inferiores a $25 \%$ e, também, que valores próximos a esses podem ser considerados críticos para sementes de espécies recalcitrantes.

A secagem de sementes de Euterpe edulis Mart. (ANDRADE; PEREIRA, 1997), Eugenia involucrata DC. (BARBEDO et al., 1998), Euterpe oleracea Mart. (MARTINS et al., 1999a), Bactris gasipaes Kunth. (BOVI; MARTINS; SPIERING, 2004) e Archantophoenix alexandrae Wendl and Drude (ANDRADE; SCHORN; NOGUEIRA, 2005) provocou decréscimo na qualidade fisiológica das mesmas.

A porcentagem máxima de plântulas na primeira contagem de emergência foi de $67 \%$ após as primeiras 16 horas, depois desse período ocorreu uma diminuição significativa e, às 144 horas os percentuais de emergência das plântulas foram nulos (Figura 3).

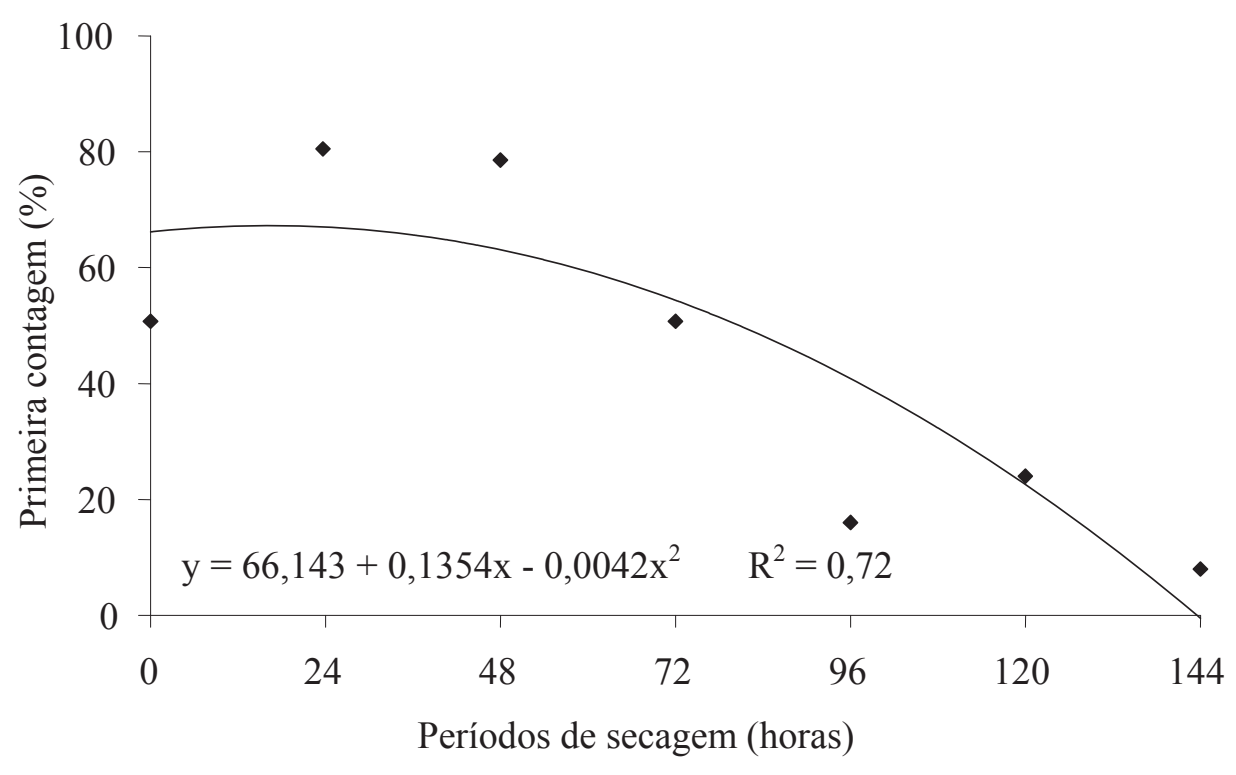

Figura 3. Primeira contagem de emergência de plântulas de Hancornia speciosa submetidas a diferentes períodos de secagem. 
A perda de água em sementes recalcitrantes desencadeia inúmeros processos deteriorativos, como a desnaturação de proteínas, alterações na atividade das enzimas peroxidases e danos no sistema de membranas, resultando, finalmente, na completa perda de viabilidade das sementes (NAUTIYAL; PUROHIT, 1985). A deterioração causada pela desidratação das sementes de palmeiras como Euterpe oleracea Mart., E. edulis Mart. e E. espiritosantensis Fernandes, (MARTINS et al., 1999a, MARTINS; NAKAGAWA; BOVI, 1999b;c) afetou também o vigor, uma vez que danifica as membranas celulares, tornando a germinação mais lenta e diminuindo o crescimento das estruturas das plântulas.

Quanto ao índice de velocidade de emergência observou-se que o maior índice $(0,62)$ foi obtido com as sementes submetidas à secagem por 21 horas, sendo que após este período a velocidade de emergência decresceu acentuadamente, chegando a valores quase nulos às 144 horas de secagem, inviabilizando o uso dessas sementes (Figura 4).

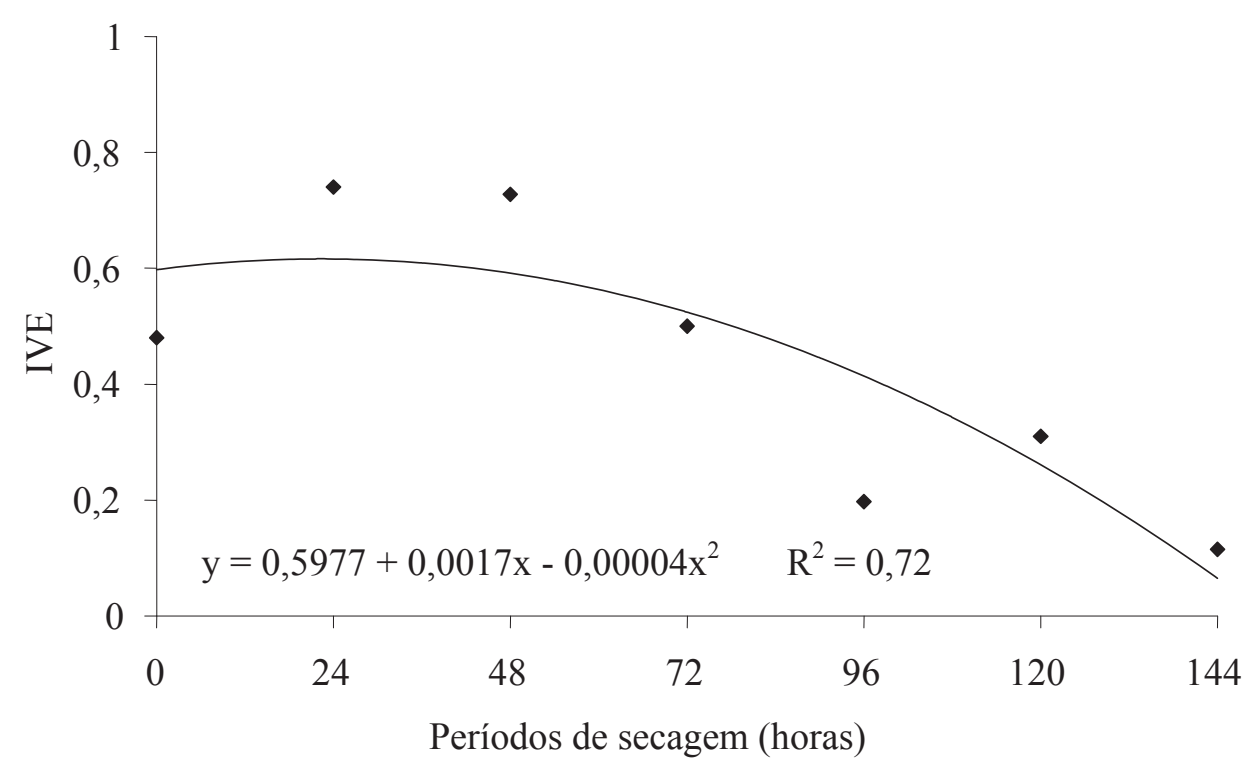

Figura 4. Índice de velocidade de emergência (IVE) de plântulas de Hancornia speciosa submetidas a diferentes períodos de secagem.

A principal consequência da deterioração de sementes é a redução da porcentagem germinação, entretanto, isto é frequentemente precedido pela redução na velocidade de germinação e emergência de plântulas (MATTHEWS, 1985). Resultados semelhantes foram obtidos com Bactris gasipaes Kunth., onde houve aumento no tempo requerido para a germinação das sementes na medida em que ocorreu a dessecação (CARVALHO; MÜLLER, 1998). Para sementes de Myrciaria dubia (H.B.K.) McVaugh Gentil, Silva e Ferreira (2004) verificaram que houve redução na velocidade de emergência de plântulas com a diminuição do teor de água de 48,3 para 33,9\%. Sementes de Inga vera Willd. tiveram seu vigor afetado quando submetidas à secagem (ALVES et al., 2008).

Constatou-se redução linear do comprimento da raiz primária das plântulas de $H$. speciosa à medida que se prolongou o período de secagem das sementes (Figura 5). Dessa forma, observou-se que a redução no teor de água das sementes impossibilitou o desenvolvimento adequado das raízes primárias das 
plântulas resultantes, uma vez que, sementes com teor de água em torno de $56 \%$ originaram raízes com comprimento médio de $8,5 \mathrm{~cm}$ e quando reduziu para $12 \%$ o comprimento foi de aproximadamente $4 \mathrm{~cm}$. Resultados semelhantes foram obtidos por Martins et al. (1999a), onde a redução do teor de água de 41 para $31,6 \%$ provocou decréscimo significativo no comprimento da radícula das plântulas de Euterpe oleracea (Mart.).

Para o comprimento da parte aérea das plântulas de $H$. speciosa oriundas de sementes submetidas a diferentes períodos de secagens (Figura 6), inicialmente registrou-se um aumento do comprimento da parte aérea $(4,96 \mathrm{~cm})$, correspondente às 56 horas de secagem; logo após este período houve uma redução no tamanho das plântulas, chegando a aproximadamente $3,5 \mathrm{~cm}$ às 144 horas. Martins et al. (1999a) também observaram que a redução do teor de água de 41 para $31,6 \%$ provocou decréscimo significativo no comprimento da parte aérea das plântulas de Euterpe oleracea (Mart.).

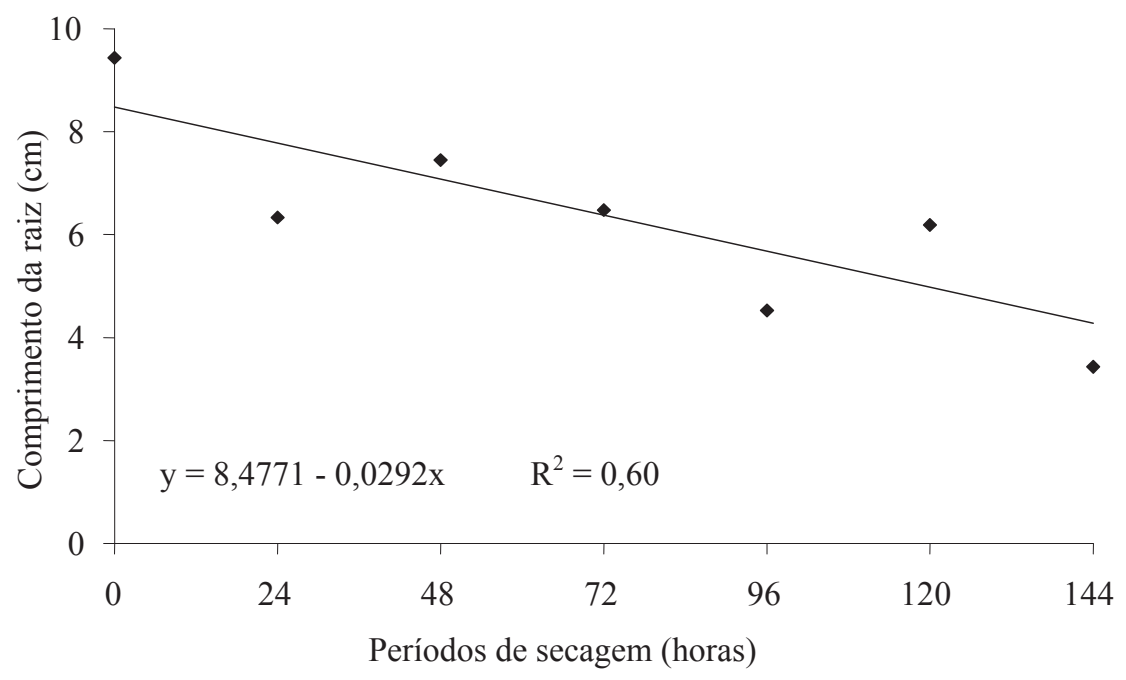

Figura 5. Comprimento da raiz primária de plântulas de Hancornia speciosa submetidas a diferentes períodos de secagem.

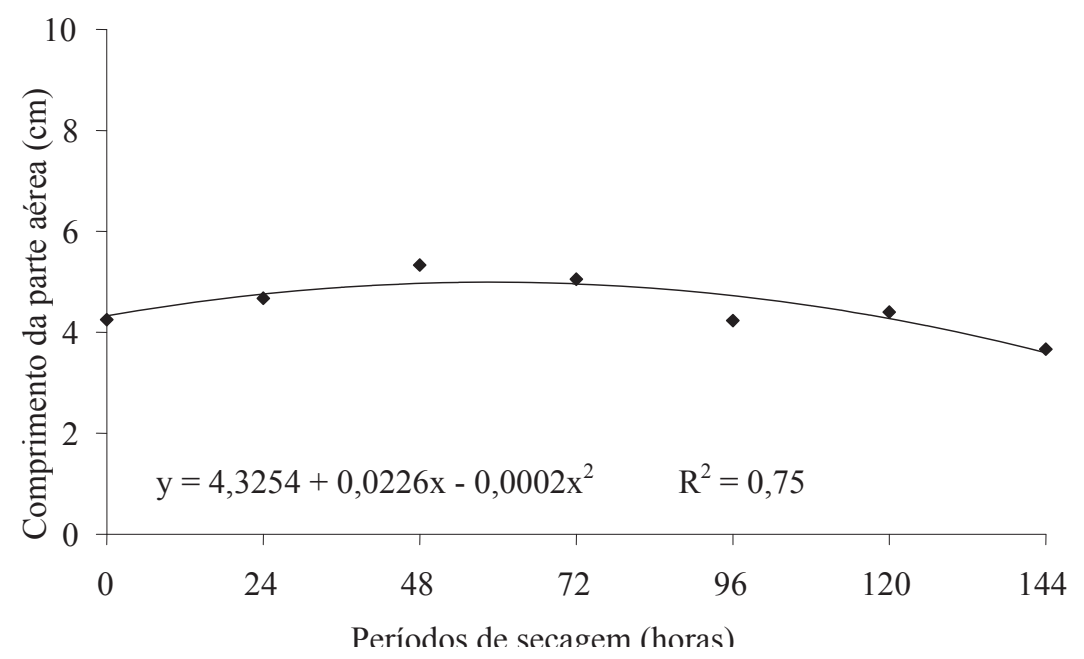

Figura 6. Comprimento da parte aérea de plântulas de Hancornia speciosa submetidas a diferentes períodos de secagem. 


\section{Conclusão}

A secagem natural das sementes de H. speciosa, em ambiente de laboratório, prejudica a emergência e o crescimento inicial das plântulas, a partir de 48 horas.

\section{Referências}

ALVES, E. U.; GUEDES, R. S.; PONTUAL, H. U.; GONÇALVES, E. P.; SILVA, K. B. Influência da secagem na germinação e vigor de sementes de Inga vera Willd. In: CONGRESSO DE PESQUISA E INOVAÇÃO DA REDE NORTE NORDESTE DE EDUCAÇÃO TECNOLÓGICA, 3., Fortaleza, 2008. Anais... Fortaleza, 2008. 1 CD-ROM.

ANDRADE, A. C. S.; CUNHA, R.; SOUZA, A. F.; REIS, R. B.; ALMEIDA, K. L. Physiological and morphological aspects of seed viability of a neotropical savannah tree, Eugenia dysenterica DC. Seed Science and Technology, Zürich, v. 31, n. 1, p. 125-137, 2003.

ANDRADE, A. C. S.; PEREIRA, T. S. Comportamento de armazenamento de sementes de palmiteiro (Euterpe edulis Mart.). Pesquisa Agropecuária Brasileira, Brasília, v. 32, n. 10, p. 987-991, 1997.

ANDRADE, R. R.; SCHORN, L. A.; NOGUEIRA, A. C. Tolerância à dessecação em sementes de Archantophoenix alexandrae Wendl. and Drude (palmeira real australiana). Ambiência, Guarapuava, v. 1, n. 2, p. 279-288, 2005.

BARBEDO, C. J.; MARCOS FILHO, J. Tolerância à dessecação em sementes. Acta Botanica Brasilica, São Paulo, v. 12, n. 2, p. 145-164, 1998.

BARBEDO, J. C.; KOHAMA, S.; MALUF, A. M.; BILIA, D. A. C. Germinação e armazenamento de diásporos de cerejeira (Eugenia involucrata DC. - Myrtaceae) em função do teor de água. Revista Brasileira de Sementes, Londrina, v. 20, n. 1, p. 184-188, 1998.

BARROS, D. I. Tecnologia de sementes de mangaba (Hancornia speciosa Gomes). 2006. Tese (Doutorado em Agronomia) - Departamento de Fitotecnia. Centro de Ciências Agrárias. Universidade Federal da Paraíba, Areia.

BERJAK, P.; PAMMENTER, N. W. What ultra structure has told us about recalcitrant seeds. Revista Brasileira de Fisiologia Vegetal, Londrina, v.12, p. 22-55, 2000. Edição Especial.

BERJAK, P.; VERTUCCI, C. W.; PAMMENTER, N. W. Effects of developmental status and dehydration rate on characteristics of water and desiccation - sensitivity in recalcitrant seeds of Camellia sinensis. Seed Science Research, Kew, v. 3, n. 3, p. 155-166, 1993.

BEWLEY, J. D.; BLACK, M. Seeds: physiology of development and germination. New York: Plenum Press, 1994. $445 \mathrm{p}$.

BILIA, D. A. C.; MARCOS-FILHO, J.; NOVEMBRE, A. D. C. L. Desiccation tolerance and seed storability of Inga uruguensis (Hook. et Arn.). Seed Science and Technology, Zürich, v. 27, n. 1, p. 77-89, 1999.

BOVI, M. L. A.; MARTINS, C. C.; SPIERING, S. H. Desidratação de sementes de quatro lotes de pupunheira: efeitos sobre a germinação e o vigor. Horticultura Brasileira, Brasília, v. 22, n. 1, p. 109-112, 2004.

BRASIL. Ministério da Agricultura e da Reforma Agrária. Regras para análise de sementes. Brasília: SNDA/DNDV/CLAV, 1992. 365 p.

CARVAlHO, J. E. U.; MÜLleR, C. H. Níveis de tolerância e letal de umidade em sementes de pupunheira, Bactris gasipaes. Revista Brasileira de Fruticultura, Jaboticabal, v. 20, n. 3, p. 283-289, 1998.

DELGADO, L. F.; BARBEDO, C. J. Tolerância à dessecação de sementes de espécies de Eugenia. Pesquisa Agropecuária Brasileira, Brasília, v. 42, n. 2, p. 265-272, 2007.

FAO. Food and fruit-bearing forest species 3: examples from Latin America. Forestry Paper, Rome, n. 43/44, p. 149-151, 1986.

FONSECA, C. E. L.; CONDÉ, R. C. C.; SILVA, J. A. Influência da profundidade de semeadura e da luminosidade na germinação de sementes de mangaba (Hancornia speciosa Gom.). Pesquisa Agropecuária Brasileira, Brasília, v. 29, n. 4, p. 661-666, 1994.

FRANCO, C. F. O.; CAZÉ FILHO, J.; BARREIRO NETO, M.; ARAÚJO, I. A.; MATIAS, E. C.; MENINO, I. B.; LIMA, I. X.; MARINHO, S. J. O.; FONTENÉLLI, I. S. C. Mangabeira (Hancornia speciosa Gomes). Disponível em: <http://www.emepa.org.br/mangaba. php>. Acesso em: 20 jan. 2008.

GENTIL, D. F. O.; SILVA, W. R.; FERREIRA, S. A. N. Conservação de sementes de Myrciaria dubia (H.B.K.) Mc Vaugh. Bragantia, Campinas, v. 63, n. 3, p. 421-430, 2004.

HARTMANN, H. T.; KESTER, D. E.; DAVIES JUNIOR, F. T.; GENEVE, R. L. Plant propagation: principles and practices. 7. ed. New Jersey: Prentice Hall. 2001. 880 p.

HONG, T. D.; ELLIS, R. H. Optimum air-dry seed storage environments for arabica coffee. Seed Science and Technology, Zürich, v. 20, n. 3, p. 547-560, 1992. 
KERMODE, A. R. Regulatory mechanisms involved in the transition from seed development to germination. Critical Reviews in Plant Sciences, Boca Raton, v. 9, n. 2, p. 155-195, 1990.

KOHOMA, S.; MALUF, A. M.; BILIA, D. A. C. Secagem e armazenamento de sementes de Eugenia brasiliensis Lam. (grumixameira). Revista Brasileira de Sementes, Pelotas, v. 28, n. 1, p. 72-78, 2006.

KOVACH, D.; BRADFORD, K. J. Imbibitional damage and desiccation tolerance of wild rice (Zizania palustris) seeds. Journal of Experimental Botany, Oxford, v. 43, n. 6, p. 747-757, 1992.

KRAAK, H. L. Physiological aspects of storage of recalcitrant seed. In: SOMÉ, L. M.; KAM, M. (Ed.). Tree seeds problems, with special reference to Africa. Leiden: [s.n.], 1993. p. 239-253.

LORENZI, H. Árvores brasileiras: manual de identificação e cultivo de plantas arbóreas do Brasil. Nova Odessa: Plantarum, 2002. 368 p.

MAGUIRE, J. D. Speed of germination aid selection and evaluation for seedling emergence and vigor. Crop Science, Madison, v. 2, n. 2, p. 176-177, 1962.

MALUF, A. M.; BILIA, D. A. C.; BARBEDO, C. J. Drying and storage of Eugenia involucrata DC. seeds. Scientia Agricola, Piracicaba, v. 60, n. 3, p. 471-475, 2003.

MARTINS, C. C.; BOVI, M. L. A.; NAKAGAWA, J. Desiccation effects on germination and vigor of King palm seeds. Horticultura Brasileira, Brasília, v. 21, n. 1, p. 88-92, 2003.

MARTINS, C. C.; NAKAGAWA, J.; BOVI, M. L. A. Desiccation tolerance of four seedlots from Euterpe edulis Mart. Seed Science and Technology, Zurich, v. 28, n. 1, p. 1-13, 1999b.

. Tolerância à dessecação de sementes de palmitovermelho (Euterpe espiritosantensis Fernandes). Revista Brasileira de Botânica, São Paulo, v. 22, n. 3, p. 391-396, 1999c.
MARTINS, C. C.; NAKAGAWA, J.; BOVI, M. L. A.; STANGUERLIM, H. Teores crítico e letal de água para sementes de açaizeiro (Euterpe oleracea Mart.). Revista Brasileira de Sementes, Londrina, v. 21, n. 1, p. 125-132, 1999a.

MATTHEWS, S. Physiology of seed ageing. Outlook of Agriculture, Wallingford, v. 14, n. 2, p. 89-94, 1985.

NAUTIYAL, A. R.; PUROHIT, A. N. Seed viability in sal. II. Physiological and biochemical aspects of ageing in seeds of Shorea robusta. Seed Science and Technology, Zurich, v. 13, n. 1, p. 69-76, 1985.

OLIVEIRA, L. M. Q.; VALIO, I. F. M. Effects of moisture content on germination of seeds of Hancornia speciosa Gom. (Apocynaceae). Annals of Botany, London, v. 69, n. 1, p. 1-5, 1992.

PAMMENTER, N. W.; BERJAK, P. Areview of recalcitrant seed physiology in relation to desiccationtolerance mechanisms. Seed Science, Research, v. 9, n. 1, p. 13-37, 1999.

PRITCHARD, H. W. Water potential and embryonic axis viability in recalcitrant seeds of Quercus rubra. Annals of Botany, London, v. 67, n. 1, p. 43-49, 1991.

SALOMÃO, A. N.; SANTOS, I. R. I.; MUNDIM, R. C. Conservação, manejo e uso de sementes de Hancornia speciosa Gomes (Apocynaceae). Brasília: Embrapa Recursos Genéticos e Biotecnologia, 2004. 26 p. (Documentos, 126).

SOUZA, C. S.; SILVA, S. A.; COSTA, M. A. P. C.; DANTAS, A. C. V. L.; FONSECA, A. A.; COSTA, C. A. L. C.; ALMEIDA, W. A. B.; PEIXOTO, C. P. Mangaba: perspectivas e potencialidades. Revista Bahia Agrícola, Salvador, v. 7, n. 1, p. 29-31, 2005.

VIEIRA NETO, R. V. Frutiferas potenciais para os tabuleiros costeiros e baixadas litorâneas. Aracaju: Embrapa Tabuleiros Costeiros/EMDAGRO, 2002. 216 p. 
